\title{
Batch Roasting on a Conveyer Sintering Machine
}

\author{
A. V. Malygin ${ }^{a}$, S. S. Golovyrin ${ }^{b}$, and S. V. Endiyarov ${ }^{b}$ \\ ${ }^{a}$ Ural Federal University, Yekaterinburg, Russia \\ ${ }^{b} \mathrm{OAO}$ Uralmashzavod, Yekaterinburg, Russia
}

Keywords: batch roasting, furnace, sintering, control

DOI: $10.3103 /$ S096709121309009X

Precise and careful monitoring and control is required when roasting sintering batch with a high content of fine concentrates in small furnaces. For such batch, the bed height employed is no more than $300-350 \mathrm{~mm}$, on account of its relatively low gas permeability. Batch roasting on a conveyer sintering machine depends on a great variety of factors, such as the characteristics of the fuel, the roasting conditions, the batch properties, and the machine's operating conditions [1-3]. Accordingly, it is difficult to determine the parameters that must be taken into account in roasting and to construct a model for use in controlling the process.

Four basic characteristics may be employed to assess the roasting process. Two of these are not used in practice: the heat received by the bed through $1 \mathrm{~m}^{2}$ of surface during its residence in the furnace produced; and its heating rate, which is the heat received per minute through $1 \mathrm{~m}^{2}$ of surface. A third, the roasting time, is determined by the length of the furnace and the machine's belt speed. Only the roasting temperature, determined from the temperature of the furnace gas, is susceptible to continuous monitoring and control. It is usually established on the basis of expert assessment and experience in operating the machine with the specific batch. As a result, excessive fuel is used in combustion, or else the cake quality is impaired with variation in the fuel's heat of combustion, the batch composition, its gas permeability, and other factors.

A new system for controlling the roasting process (illustrated in the figure) is undergoing tests in sintering plants 2 and 3 at OAO Magnitogorskii Metallurgicheskii Kombinat (MMK). The system includes calculations of the heat consumed for sintering and the quantity of heat supplied by the furnace. If the heat supplied is less than the heat consumed, the heat supply is increased; conversely, if the heat supplied is more than the heat consumed, the heat supply is reduced.

The rates of gas and air consumption in combustion are the output parameters that are changed in regulation. Their ratio determines the temperature of the furnace gas and the roasting rate. Ideally, the quantity of gas formed during fuel combustion is the furnace is equal to the quantity of gas sucked through the bed, so that no cold air is drawn through the bed and no furnace gas is released to the working area of the machine. In that case, the rate $I\left(\mathrm{~kJ} /\left(\mathrm{m}^{2} \mathrm{~min}\right)\right)$ at which the batch is roasted is

$$
I=\dot{\omega}_{0} c_{\mathrm{g}} t_{\mathrm{g}},
$$

where $\dot{\omega}_{0}$ is the mean velocity of the gas leaving the hearth and correspondingly sucked into the bed, $\mathrm{m}^{3} /\left(\mathrm{m}^{2} \mathrm{~min}\right) ; c_{\mathrm{g}}$ is the specific heat of the gas, $\mathrm{kJ} /\left(\mathrm{m}^{3} \mathrm{deg}\right)$, at temperature $t_{\mathrm{g}},{ }^{\circ} \mathrm{C}$.

The total quantity of heat $Q$ obtained by $1 \mathrm{~m}^{2}$ of bed in its residence time within the furnace is

$$
Q=I \tau_{\text {ro }}=\left(l_{\mathrm{f}} / V_{\mathrm{sm}}\right) \dot{\omega}_{0} \dot{c}_{\mathrm{g}} t_{\mathrm{g}},
$$

where $\tau_{\text {ro }}$ is the roasting time of the batch, $\min ; l_{\mathrm{f}}$ is the furnace length, $\mathrm{m} ; V_{\mathrm{sm}}$ is the speed of the conveyer belt in the sintering machine, $\mathrm{m} / \mathrm{min}$.

The belt speed must ensure complete sintering

$$
V_{\mathrm{sm}}=L_{\mathrm{sz}} / \tau,
$$

where $L_{\mathrm{sz}}$ is the length of the sintering zone in the machine, $\mathrm{m}$; $\tau$ is the sintering time of the batch bed, min.

Therefore

$$
Q=\left(l_{\mathrm{f}} / L_{\mathrm{sz}}\right) \tau \dot{\omega}_{0} \dot{c}_{\mathrm{g}} t_{\mathrm{g}} .
$$

The sintering time may be determined as the sum of the times for each stage of the process

$$
\tau=\tau_{\mathrm{s}}+\tau_{\mathrm{ig}}+\tau_{\mathrm{co}},
$$

where $\tau_{\mathrm{s}}$ is the time for batch sintering; $\tau_{\mathrm{ig}}$ is the time for the motion of the fuel's ignition front in the bed from its surface to the grate (or to the supporting surface); $\tau_{\text {co }}$ is the time for complete combustion of the fuel in the lower part of the bed after the ignition front reaches the grate.

The combustion time $\tau_{\mathrm{co}}$ depends primarily on the surface area of the fuel particles and is $1-2 \mathrm{~min}$ if the 


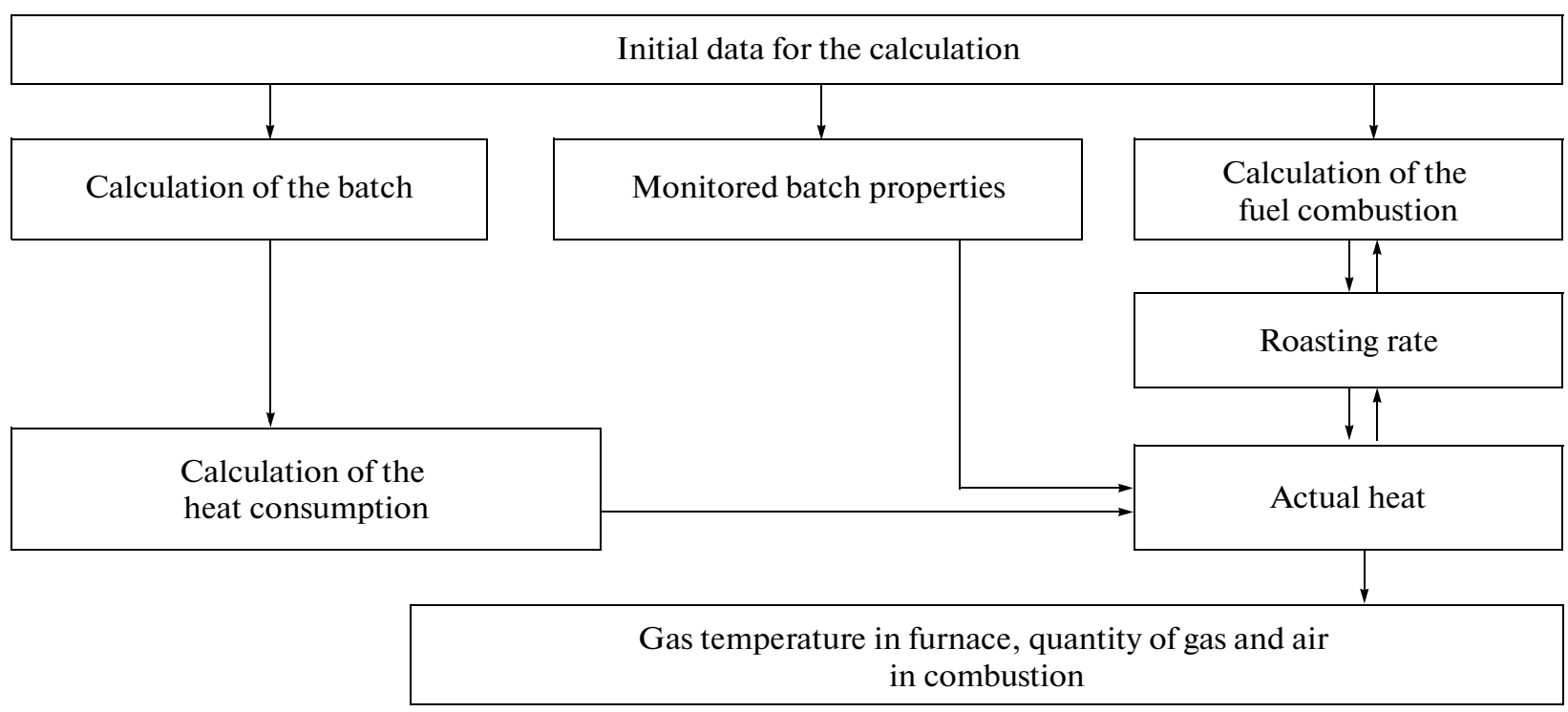

Control of the sintering process.

particles are no larger than $3 \mathrm{~mm}$. If we disregard the time required for solidification of the melt, most of the sintering time is associated with the motion of the thermal wave through the bed, especially with a considerable bed height. The time for the ignition front to travel from the surface to the bottom of the bed is

$$
\tau_{\mathrm{ig}}=H / V_{\mathrm{ig}},
$$

where $H$ is the bed height, $\mathrm{m} ; V_{\text {ig }}$ is the velocity of the ignition front, $\mathrm{m} / \mathrm{min}$.

The speed of the ignition front may be derived from the thermal balance in the lower part of the intenseheating zone

$$
V_{\text {ig }}=\left(1 / \gamma_{\mathrm{b}}\right)\left(C_{\mathrm{g}} / C_{\mathrm{b} . \mathrm{a}}\right) \omega_{0},
$$

where $\gamma_{\mathrm{b}}$ is the density of the batch, $\mathrm{kg} / \mathrm{m}^{3} ; C_{\mathrm{g}}$ is the mean specific heat of the gas in the lower heat-transfer zone at $400-1000^{\circ} \mathrm{C}, \mathrm{kJ} /\left(\mathrm{m}^{3} \mathrm{deg}\right) ; C_{\mathrm{b} . \mathrm{a}}$ is the mean apparent specific heat of the batch at $100-750^{\circ} \mathrm{C}$, $\mathrm{kJ} /(\mathrm{kg} \mathrm{deg}) ; \omega_{0}$ is the filtration rate of the gas through the bed, $\mathrm{m}^{3} /\left(\mathrm{m}^{2} \mathrm{~min}\right)$.

Substituting Eq. (7) into Eq. (6), we obtain

$$
\tau_{\mathrm{ig}}=H \gamma_{\mathrm{b}}\left(C_{\mathrm{b} . \mathrm{a}} / C_{\mathrm{g}}\right) / \omega_{0} \text {. }
$$

\section{Given that}

$$
\tau=\tau_{\mathrm{s}}+\tau_{\mathrm{co}}+H \gamma_{\mathrm{b}}\left(C_{\mathrm{b} . \mathrm{a}} / C_{\mathrm{g}}\right) / \omega_{0},
$$

we may write

$$
\begin{aligned}
& Q=\left(l_{\mathrm{f}} / L_{\mathrm{sz}}\right)\left[\tau_{\mathrm{s}}+\tau_{\mathrm{co}}+H\right. \\
& \left.\times \gamma_{\mathrm{b}}\left(C_{\mathrm{b} . \mathrm{a}} / C_{\mathrm{g}}\right) / \omega_{0}\right] \dot{\omega}_{0} \dot{c}_{\mathrm{g}} t_{\mathrm{g}} .
\end{aligned}
$$

It is evident from Eq. (10) that the heat $Q$ received by $1 \mathrm{~m}^{2}$ of bed in its furnace residence time may be increased by increasing the furnace length, reducing the length of the sintering zone $\left(L_{\mathrm{sz}}\right)$, and increasing the gas temperature. The influence of the air filtration rate on $Q$ is more complex. With increase in $\omega_{0}$, the sintering time is reduced, and hence $Q$ is reduced. On the other hand, the filtration rate of the gas through the bed in the furnace $\left(\dot{\omega}_{0}\right)$ usually increases proportionally with increase in $\omega_{0}\left(\dot{\omega}_{0}=k \omega_{0}\right)$. That increases the sintering rate and hence increases $Q$.

The filtration rate of the gas through the bed in the furnace may be reduced by throttling the vacuum chamber. However, in this process, engineering difficulties arise in the first vacuum chambers of the machine on account of the high dust and moisture content of the gas flux. Therefore, the heat received by $1 \mathrm{~m}^{2}$ of batch surface in the furnace may be regulated by three independent parameters: the temperature of the gas, the length of the furnace, and the length of the sintering zone in the machine. However, reducing the length of the sintering zone by reducing the belt speed impairs the productivity. Accordingly, the heat supply to the bed may only be regulated in practice by the gas temperature, whose fluctuation at constant fuel composition depends on the gas-air ratio. Since the gas temperature must ensure the required melting of the batch surface, it may be varied only within a relatively narrow range $1150-1300^{\circ} \mathrm{C}( \pm 6.5 \%$ of the mean temperature $t$ ).

The heat consumption in roasting and in creating a margin for sintering beyond the furnace depends on the moisture content of the batch, its density, the content of limestone and solid fuel in the surface layer, and other factors. At least three of the parameters determining the heat consumption-the thickness of the 
surface layer heated to specified temperature (usually $1000^{\circ} \mathrm{C}$ ), the temperature, and the degree of surface melting of the batch-must be specified on the basis of experiments or practical experience in sintering. In the case of fluxed magnetite batch, the heat consumption is increased by $20-25 \%$ on increasing the thickness of the surface layer heated to $1000^{\circ} \mathrm{C}$ from 20 to $30 \mathrm{~mm}$. Increasing the temperature from 1000 to $1200^{\circ} \mathrm{C}$ results in $10-15 \%$ increase in heat consumption. Increasing the degree of batch melting from 30 to $60 \%$ is associated with $8-12 \%$ increase in heat consumption. If the temperature is raised to $1200^{\circ} \mathrm{C}$ and in addition the batch melting is increased from 30 to $60 \%$, the total increase in heat consumption is $18-$ $27 \%$. This considerably expands the scope for adjusting the heat supply by varying the gas temperature.

Accordingly, with constant furnace length and without regulation of the gas's filtration rate through the bed, the heat consumption is the basic parameter that may be adjusted to prevent inadequate values of the heat supplied, in the case of increased basicity or moisture content of the batch, say. Monitoring of the heat consumption for sintering permits analysis and optimization of the process.

Thus, the proposed approach to the monitoring and regulation of sintering permits the determination of the relevant parameters and their permissible ranges and may be used in the design of furnaces and control systems for batch sintering. This approach may be adopted as part of a comprehensive control system for sintering on conveyer machines.

\section{REFERENCES}

1. Korotich, V.I., Frolov, Yu.A., and Kaplun, L.I., Teoreticheskie osnovy tekhnologii okuskovaniya metallurgicheskogo syr'ya (Theoretical Principles in the Sintering of Metallurgical Materials), Yekaterinburg: GOU VPO Ural'skii Gosudarstvennyi Tekhnicheskii Universitet-UPI, 2005.

2. Basilevich, S.V. and Vegman, E.F., Aglomeratsiya (Sintering), Moscow: Metallurgiya, 1967.

3. Frolov, Yu.A., Thermal aspects of the initial stage of sintering, Stal', 2004, no. 1, pp. 2-10.

Translated by Bernard Gilbert 